\title{
SICKLE CELL TRAIT AS A CAUSE OF SPLENIC INFARCTION AT HIGH ALTITUDE
}

Wijesinghe WDUM, Sirigampala C

Colombo North Teaching Hospital, Ragama, Sri Lanka

DOI: http://doi.org/10.4038/sljr.v2i2.58

Key words:Sickle cell trait, High altitude, Splenic infarct

\section{Introduction}

Splenic infarction is a well-recognized complication in people with sickle cell trait which occurs when exposed to low Oxygen tension environments like travelling in unpressurized aircrafts and exercising at a high altitude. Usually, these patients are initially diagnosed as sickle cell trait following development of such complications. Sickle cell trait is otherwise an asymptomatic condition. We report a case of a 26 year old native Sri Lankan male who developed a splenic infarction while climbing a mountain.

\section{Case report}

A previously healthy 26 year old male developed severe left hypochondrial pain after climbing to the top of a mountain, the Adam's peak, which has an altitude of $2243 \mathrm{~m}$. Initially he presented to a peripheral health care institution where he was treated with analgesics and antacids for three days. He was then transferred to a tertiary healthcare centre as his left hypochondrial pain got worse. Pain was exacerbated with respiratory movements and he developed fever, nausea and vomiting. He did not have chest, muscle or joint pains. There was no history of similar episodes in the past. There was no family history of haematological disorders requiring blood transfusions. On the fourth day he developed tea coloured urine. On examination he looked ill, with a body temperature of $103 \mathrm{~F}$. He was icteric but not pale. He had tachycardia and his blood pressure was 150/80 $\mathrm{mmHg}$. There was mild cardiomegaly and reduced air entry in the left lower zone of the lung with bronchial breathing. Abdominal examination revealed mild tender splenomegaly. The biochemical investigations showed a normal full blood count initially, but over a week the platelet count had risen from 150000 to

Corresponding author:Wijesinghe WDUM < w.uditha@yahoo.com>

iD http://orcid.org/0000-0002-0299-6150

This is an open-access article distributed under the terms of the Creative Commons Attribution License, which permits unrestricted use, distribution, and reproduction in any medium, provided the original author and source are credited. 
3

925000/ $\mathrm{mm}$ and the WBC count increased from 9500 to 18000 . The blood picture showed normal red blood cell morphology at this point.

The chest radiograph revealed consolidation in the basal segments of the left lower lobe and a small pleural effusion (Figure 1). Ultrasound scan of the abdomen showed an enlarged spleen (length $-14.8 \mathrm{~cm}$ ) with a subcapsular hypoechoic area containing a few septae (Figure 2). The rest of the spleen showed normal echogenicity and architecture. Sonography also confirmed the small pleural effusion on left side with underlying lung consolidation. There was no intraperitoneal fluid.

A provisional diagnosis of subcapsular splenic collection was made. Contrast enhanced CT (CECT) of the abdomen acquired in the portal venous phase revealed an enlarged spleen with a large nonenhancing area in the subcapsular region (Figure 3). Enhancing septae and vessels were seen running through the nonenhancing area towards the capsule. There was enhancement of the splenic capsule. A small amount of enhancing splenic tissue was seen close to the hilum. The splenic vein, the splenic artery and its branches close to the hilum appeared patent within the limitations of portal venous phase study. The CT appearances were consistent with a large splenic infarction.

Haemoglobin analysis revealed $\mathrm{HbS}$ percentage of 38.6 and $\mathrm{HbA}$ percentage of 50.8 raising the possibility of the diagnosis of sickle cell trait in this patient.
The patient was managed conservatively with bed rest, IV fluids, antipyretics and oxygen via face mask. IV antibiotics, ceftriaxone and clarithromycin, were prescribed during the acute phase of the illness. The patient underwent regular chest physiotherapy. Antiplatelet prophylaxis was provided with aspirin $75 \mathrm{mg}$ daily. The patient's condition improved over the next two weeks.

\section{Discussion}

Sickle cell disease is the most common haemoglobinopathy in the world, though it is mainly seen in the people of Sub-Saharan Africa and their descendants including African Americans. The genetic basis of the disease is a single base substitution in the gene coding B-globin chain leading to the sixth amino acid glutamic acid being substituted by valine. Resultant abnormal haemoglobin is known as $\mathrm{HbS}$. It is inherited in an autosomal co-dominant manner. The presence of two abnormal genes cause sickle cell disease while the presence of one abnormal gene causes sickle cell trait ${ }^{1,2}$. People with sickle cell trait usually remain asymptomatic. They have normal haemoglobin levels and they do not develop complications associated with sickle cell anaemia under normal circumstances . This is because, under normal atmospheric pressure and oxygen concentrations, the percentage of $\mathrm{HbS}$ in their RBCs is inadequate to cause sickling. However, their red blood cells (RBC) can develop sickling when the blood oxygen tension drops due to various causes. As in this case, strenuous exercise at a high altitude where the 
atmospheric pressure is low compared to the sea level, the deoxygenated $\mathrm{HbS}$ can polymerize causing the red blood cells to sickle. The inflexible sickled RBC clog up the capillaries causing infarctions. The spleen is a common site for this process to take place as local tissue environment is suited for that. The most common cause of splenic infarcts in sickle cell trait has been flying in unpressurized aircrafts while the next common cause is mountaineering. This association was first established when a large number of African American servicemen developed splenic infarcts when flying in unpressurized aircrafts during Korean War. Following the precipitating event, the patient develops severe abdominal pain in the left upper quadrant within few hours and nausea, vomiting and fever follow.

There is usually associated left sided pleural effusion and underlying segmental atelectasis of the lung. Clinical examination may show tender splenomegaly with guarding. Within the first three days, there is mild leukocytosis, mild anaemia and elevation of $\mathrm{LDH}$.

The best imaging modality to demonstrate splenic infarction is CECT of the abdomen which shows large areas of haemorrhage in the early stages. These are non-enhancing and become hypodense with time, as in this case, where the CT scan was done a few days after the event. The other conditions that can give a similar imaging appearance include traumatic splenic haemorrhage and infarcts in myeloid metaplasia where the clinical history helps in differentiation.
Splenic infarcts due to thromboembolic conditions and endocarditis are readily differentiated on appearance as they appear as multiple tiny non enhancing foci .

The management of splenic infarction in sickle cell trait is supporting care with analgesics, oxygen and rest. Usually resolution occurs over 2 to 3 weeks. Vaccination against Streptococcus pneumoniae and Haemophilus influenza should be given. There is a rare possibility of splenic rupture warranting splenectomy, but this was not found in our patient ${ }^{6.7 .8 .9}$.

\section{Conclusion}

Sickle cell trait is an asymptomatic condition which can cause splenic infarctions in otherwise healthy patients at high altitudes. The typical presentation should alert the managing physicians about the possibility of the diagnosis. When correctly diagnosed with the aid of imaging, this condition can be managed conservatively as in this case and unnecessary surgicalintervention can be prevented.

Acknowledgement: We thank the Haematologist at North Colombo Teaching Hospital for the contribution made for this case report.

Conflict of interest:We declare that there is no conflict of interest among authors. 


\section{References:}

1. Johnson LN.Sickle cell trait: an update.Journal of the National Medical Association. 1982;74(8):7517.

2. Bunn HF. Pathogenesis and treatment of sickle cell disease.New England Journal of Medicine.1997 11;337(11):762-9.

3. Funakoshi H1, Takada Tetel.Sickle cell trait as a cause of splenic infarction while climbing Mt. Fuji. Journal of internal medicine. 2010;49(16):1827-9.

4. Kark JA, Ward FT. Exercise and hemoglobin S. Seminars in Hematology.1994 ; 31(3): 181.

5. Kark J. Sickle cell trait. Howard University School of Medicine Centre for Sickle Cell Disease.2000; 2121.

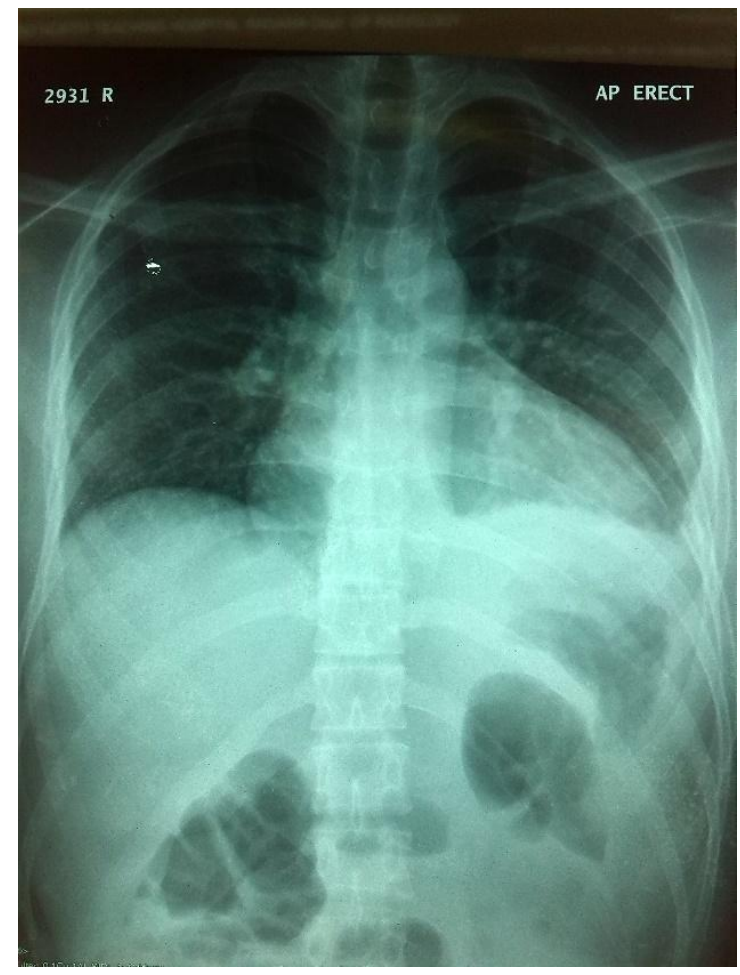

6. Claster S, Vichinsky EP. Managing sickle cell disease.British Medical Journal.2003 15;327(7424):1151.

7. Franklin QJ, Compeggie M. Splenic syndrome in sickle cell trait: four case presentations and a review of the literature. Military Medicine.1999 ;164(3):230.

8. Tsaras G, Owusu-Ansah A, Boateng FO, Amoateng Adjepong Y.

Complications associated with sickle cell trait: a brief narrative review. The American Journal of Medicine. 2009;122(6):507-12.

9. Morishima A, Schofer JM, Pelletier P, McKee JM. Images in emergency medicine: splenic infarction due to sickle cell trait after climbing Mt. Fuji. Western Journal of Emergency Medicine.2008;9(3).
Figure 1: Chest radiograph- consolidation in basal segments of $L / L o w e r$ lobe and a pleural effusion 

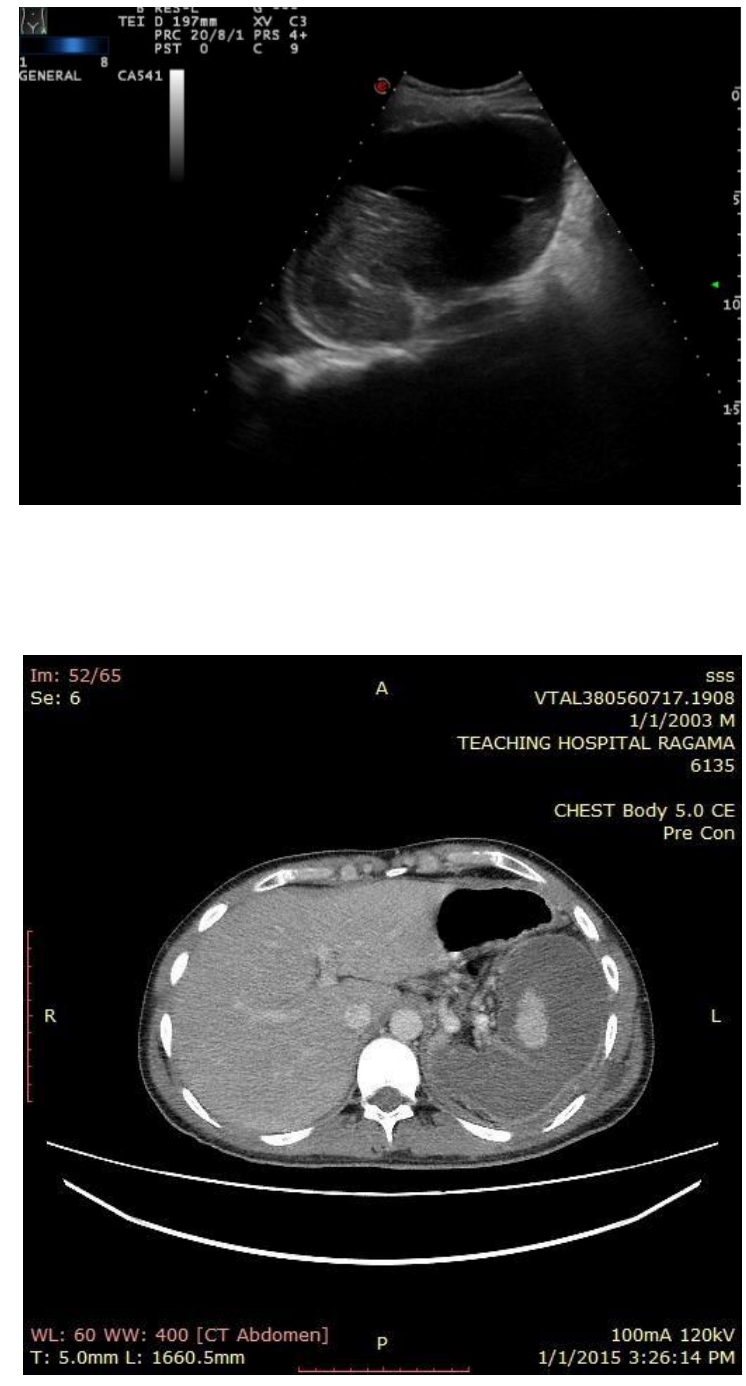

Figure 2: Ultrasound scan of abdomensplenomegaly and subscapsular hypoechogenic area with a few septae

Figure 3: CT abdomen (portal venous phase) splenomegaly with a large non enhancing areas in the subcapsular region 